\title{
Do Men Yawn More Than Women?
}

Gabriele Schino

Istituto di Psicologia del CNR, Reparto di Psicologia Comparata, Rome, Italy

Filippo Aureli

Laboratorium voor Vergelijkende Fysiologie, Rijksuniversiteit Utrecht, The Netherlands, and Cattedra di Ecologia ed Etologia Animale,Università di Roma "La Sapienza"

Among primates, yawning is a widespread behvior, although it occurs at low frequency. Different hypotheses have been formulated about its possible functions (Hadidian 1980). Since the most serious injuries in primates are usually caused by biting, yawning may be an intimidating display of the teeth toward potential antagonists.

In all the species of nonhuman primates for which data on sex differences in the frequency of yawning are reported, males yawn much more than females (Bertrand 1969; Deputte 1978; Goy and Resko 1972; Hadidian 1980; HA and DeVore 1965; Redican 1975; Rinaldi 1985; Wolfheim and Rowell 1972). This différence has been related to sexual dimorphism in canine size: The larger size of male canines may make the male yawn a more effective threat.

The aim of the present study was to test the hypothesis that the sex differences in the frequency of yawning are related to sexual dimorphism in canine size. To this end, the comparative method was used (Eibl-Eibesfeldt 1974; Maynard Smith 1978). All the primate species for which delailed data on yawning behavior are available are sexually dimorphic, but Homo sapiens is a species with minimal canine dimorphism (Leutenegger and Kelly 1977). To date, the only study reporting data on sex differences in human yawning was done in an experimental setting (Provine and Hamernik 1986). Thus, a naturalistic study of yawning by Homo sapiens was needed to test the hypothesis that a minimally dimorphic species does not show sex differences in the frequency of yawning.

A further aim of the present study consists of providing quantitative data on the spontaneous behavior of humans. Such data are still rare in human ethology (McGuire and Fairbanks 1977). A detailed description of human spontaneous behavior seems to be a necessary first step to reach a full comprehension of the causation and function of human behavior.

Subjects of the present study were passengers of the B line of the Rome underground. We chose this observational setting for two main reasons: 1) It provides observational conditions that are extremely favorable (visibility of the subjects is excellent; moreover, since passengers canne look through the windows, it is considered normal to look at other people); and 2) most of the subjects are unfamiliar to each other, a situation that might elicit slightly assertive behaviors.

Data were collected during 94 underground journeys between May 12, 1986, and March 7,1987 . The duration of the journeys was $15 \pm 2.87$ minutes $(\mathrm{M} \pm \mathrm{SD})$. Observations were made between 8 A. M. and 9 P. M. At the beginning and at the end of each observational session, i.e., of each journey, the observer counted the men and the women present in the section of the carriage chosen for the observation. The proportion of men (100 X [total number of men - total number of men + total number of women]) was considered to be an estimate of the relative percentage of the 
males and the females who were present on the underground during the data collection. Journeys in which the carriage was excessively crowded were excluded from data collection because of the poor visibility of the subjects. Since only adult nonhuman primates are reported to show sex differences in yawning behavior (e.g., Hadidian 1980), subjects whose visually estimated age was under 18 years were excluded from data collection.

The sampling method was complete recording (Slater 1978). Yawning was formally defined as a gaping movement of the mouth accompanied by a long inspiration followed by a shorter expiration (Provine et al. 1987). Two different types of yawn were distinguished: a) The subject yawns without any attempt to hide or cover his/her action; and b) the subject covers, partially or completely, his/her mouth with a hand, or yawns incompletely with a partially open mouth. The observer recorded the sex of the actor and the type of each yawn.

The relative percentages of males and females present on the underground during the data collection were $59.3 \%$ and $40.7 \%$, respectively.

A total of 267 yawns by 221 different subjects were recorded; $57.9 \%$ and $42.1 \%$ of the subjects who yawned were males and females, respectively. The expected distribution of the yawns between males and females based on their relative presences on the underground was thus indistinguishable from the observed one $\left(X^{2}=0.1605, \mathrm{~N}=221, \mathrm{df}=1, \mathrm{~N}\right.$. S.).

These data indicate that adult human males and females, unlike several nonhuman primate species, do not differ in the frequency of yawning. These results are congruent with sex différences in canine size. Even if correlational data do not demonstrate a direct cause-effect relationship, these data suggest that sex différences in frequency of yawning by primates may be related to the sex dimorphism in canine size.

Males and females displayed the two types of yawn in different proportions: $49.2 \%$ of male and $32.6 \%$ of fernale subjects who yawned showed uncovered (type a) yawns $\left(\mathrm{X}^{2}=5.049, \mathrm{~N}\right.$ $=208, \mathrm{df}=1, \mathrm{p}<0.05$; subjects who showed both types of yawn were excluded from this analysis).

The most conspicuous form of this display is, thus, used more by males than by females. Hence, human males seem still to behave in a more assertive way, even if they do not appear to differ from females either in canine size or in the total frequency of yawning. Alternatively, human females may be more "polite" than males.

Several studies have reported a direct influence of testosterone on yawning by nonhuman primates (Bielert 1978; Goy and Resko 1972; Wallen and Goy 1977). The plasma testosterone concentration of human males is higher during the early morning than during the evening (e.g., Rose et al. 1972). In our study, the frequency of men's yawns recorded between 8 A.m. and 10:30 A.M. (0.543 \pm 0.624 yawns/hour/male subject $)$ did not differ significantly from that recorded between 6:30 P.m. and 9 P.m. (0.593 0.766 yawns/hour/ male subject) (Mann Whitney U test; $\mathrm{U}=248.5$, NI 22, N2 = 23; sec also Provine et al. 1987; Baenninger 1987). Therefore, even if data on diurnal variations have to be interpreted cautiously, this analysis seems to indicate that human yawning behavior has become independent from the influence of testosterone, given the absence of sex différences in the frequency of yawning. 
In conclusion, the present study demonstrates that human beings, unlike more dimorphic primates, do not show sex differences in the frequency of yawning. Data on a wider variety of contexts would be necessary to dismiss definitively the possibility of any sex différence in the frequency of human yawning. Data from Provine and Hamernik (1986), though gathered in an entirely different situation, did not reveal any male-female différence in the frequency of yawning. If confirmed, these results would suggest that sex differences in primate yawning behavior may be associated with sexual dimorphism in canine size.

\section{References}

1. Baenninger, R. Some comparative aspects of yawning in Betta spiendens, Homo sapiens, Panthera leo, and Papio sphinx. Journal of Comparative Psychology 101: 349-354, 1987.

2. Bertrand, M. The Behavioral Repertoire of the Stuptail Macaque, Basel: S. Karger, 1969.

3. Bielert, F. Androgen treatments of young rhesusmonkeys. In Recent Advances in Primatology, Vol. 1, D.J. Chivers, J. Herbert (Eds.). New York: Academic Press, 1978, pp. 485-488.

4. Deputte, B. Etude du bâillement chez deux espèces de Cercopithecidae, Cercocebus albigena albigena GRAY et Macaca fascicularis RAFFLES: Recherche des facteurs de causalité et de fonction. Mise en evidence des facteurs socio-bioénergétiques. Thesis, L'Université de Rennes, 1978.

5. Eibl-Eibesfeldt, 1. Grundriss der vergleichenden Verhaltensforschung. Etologie, München: R. Piper \& Co. Verlag, 1974.

6. Goy, R.W., and Resko, G.A. Gonadal hormones and behavior of normal and pseudohermaphroditic nonhuman female primates. Recent Progress in Hormone Research 28: 707733, 1972.

7. Hadidian, J. Yawning in an old world monkey, Macaca nigra (Primates: Cercopithecidae). Behaviour 75: 133-147, 1980.

8. Hall, K.R.L., and DeVore, 1. Baboon social behavior. In Primate Behavior, 1. DeVore (Ed.). New York: Holt, Rinehart \& Winston, 1965, pp. 53-110.

9. Leutenegger, W., and Kelly, J.T. Relationship of sexual dimorphism in canine size and body size to social, behavioral, and ecological correlates in anthropoid primates. Primates 18:117136, 1977.

10. Maynard Smith, J. Optimization theory in evolution. Annual Review of Ecology of Systematics 9: 31-56, 1978.

11. McGuire, M.T., and Fairbanks, L.A. Ethology: Psychiatry's bridge to behavior. In Ethological psychiatry, M.T. McGuire, L.A. Fairbanks (Eds.). New York: Grune and Stratton, 1977, pp. 1-40. 
12. Provine, R.R., and Hamernik, H.B. Yawning: effects of stimulus interest. Bulletin of the Psychonomic Society 24: 437-438, 1986.

13. Provine, R.R., Hamernik, H.B., and Curchack, B.C. Yawning: Relation to sleeping and stretching in humans. Ethology 76: 152-160, 1987.

14. Redican, W.K. Facial expression in nonhuman primates. In Primate Behavior, Vol. 4, L.A, Rosenblum (Ed.). New York: Academic Press, 1975, pp. 103-194.

15. Rinaldi, F. Attività di spostamento del macaco del Giappone (Macacafuscata). Tesi di Laurea, Università di Roma "La Sapienza, 1985.

16. Rose, R.M., Kreuz, L.E., Holaday, J.W., Sulak, K.J., and Johnson, C.E. Diurnal variation of plasma testosterone and cortisol. Journal of Endocrinology 54: 177-178, 1972.

17. Slater, P.J.B. Data collection. In Quantitative Ethology, P.N. Colgan (Ed.). New York: John Wiley \& Sons, 1978, pp. 7-24.

18. Wallen, K., and Goy, R.W. Effects of estradiol benzoate, estrone, and propionate of testosterone or dihydrotestosterone on sexual and related behaviors of ovariectomized rhesus monkeys. Hormones and Behavior 9: 228-248, 1977.

19. Wolfheim, J.H., and Rowell, T.H. Communication among captive talapoin monkeys (Miopithecus talapoin). Folia Primatologica 18: 224-255, 1972.

The aim of this study was to test the hypothesis that sex differences in primate yawning are related to size dimorphisin in canine teeth. Data were collected on yawning by a primate species (Homo sapiens) in which the two sexes differ only slightly in canine size. Unlike more dimorphic primates, human males and females did not differ in the frequency of yawning, although uncovered yawns were more frequent in men than in women. 